VARIA

\title{
CROWDSOURCING: A CRITICAL DISCUSSION ON SOME ISSUES OF A CHALLENGING NEW PRACTICE IN THE DIGITIZATION OF PHOTOGRAPHIC HERITAGE
}

\author{
Jan Baetens ${ }^{1}$
}

This article deals with a certain number of issues raised by the use of crowdsourcing in the management of photographic archives. Although crowdsourcing is (and should remain) a vital instrument in the description and analysis of photographic material, it does not really take into account certain problems such as the difference between information and knowledge, the reduction of knowledge to merely cognitive elements (at the expense of social, political, and ideological belief systems) and the creative tension between the unique artefact on the one hand and serialization on the other hand. Relying on the work by Yves Citton and his plea for the role of interpretation in humanist research, this article will offer a new way of "framing" the technique of crowdsourcing in a larger interpretive context.

Crowdsourcing, that is "the process of obtaining needed services, ideas, or content by soliciting contributions from a large group of people, and especially from an online community, rather than from traditional employees or suppliers" (wikipedia), is a crucial issue in the world of

1 Jan Baetens is Full Professor of Literary Theory and Cultural Studies at Katholieke Universiteit Leuven.

Recherches en communication, $\mathrm{n}^{\circ} 42$ (2016). 
heritage culture, more specifically in that of the organization, use and public appropriation of digital photographic heritage. Unlike other forms of visual heritage, photographic documents are almost inherently vulnerable to both a lack and an excess of meaning. First because photography is by definition a medium that produces documents whose meaning is open to many different interpretations (hence for instance the necessity to add captions if one wants to secure a certain interpretation). Second, because the migration to digital archives tends to increase even more this fundamental openness (since many photographs enter the archive without clear or complete captions, the rupture between the original situation in which the picture was taken and the context in which it reemerges today is often so great that it becomes difficult to make sense of what is discovered by contemporary viewers).

Imagine, by way of a thought experiment ${ }^{1}$, the following picture pops up on your screen, uncaptioned, non-contextualized, deprived of any complementary information:

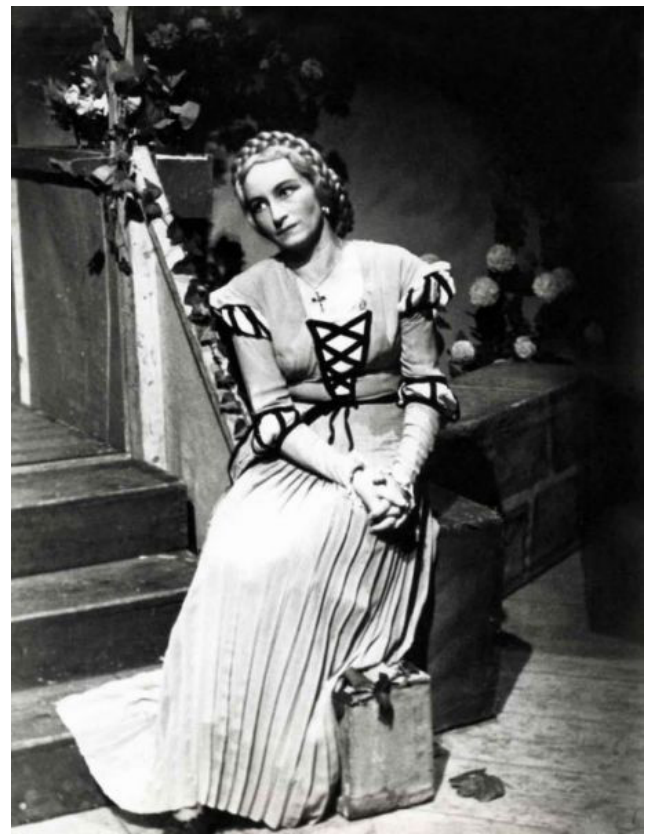

Image 1

1 Currently available information on this picture will be given below, where it will become clear as well in which larger context the image has been chosen as an example. 
This picture will raise a wide range of inevitable questions. Some of them may have to do with the image itself: Whom does it represent? When was it made? Who commissioned it? What is it size? Other questions will refer to the picture's meaning: Even if we think we recognize more or less what it represents, we do not know therefore what the image actually means, and to whom it does so. And how do we know how the image's meaning has shifted over time? What is the relationship of this picture with the time and place where it first appeared? A third group of questions derives from the fact that this image is not the original picture and that as all cultural objects it has a material and editorial history. Since this image has been selected, on purpose or not, to be part of a digital collection ore environment, we want to know who decided to choose this specific image, how the process of archiving and digitizing was organized, and last but not least we also want to know what to think of its reuse as an "example", for instance in this talk, given by someone has already published on the countless paradoxes and surprises of working with examples and case studies (Baetens, 2011).

To many of these questions, crowdsourcing is supposed to give at least partial (and partially satisfying) answers. Users can indeed help fill in some of the missing data. It is perfectly thinkable that committed or simply interested prosumers will provide us with the information we need to identify what this picture is about. They will teach us that it shows Margita Ėesányiová, a member of the Slovak National Theatre, that it shows her in the role of Margarethe in Charles Gounod's Faust, and that the picture was taken in 1938. Besides, the crowdsourcers will be happy to testify as well of what this image might have signified in these years or still signify today. Some may even go beyond collective or subjective interpretations and suggest some advanced reading, thus clearing new ground for new readings. They may mention the Bianca Castafiore character in King Ottokar's Scepter, the eighth Tintin album, which started publication as an instalment story in 1938 (the year of the picture's making) and where Gounod's opera is an important part of both the story and the setting. Or they may think of Greta Garbo, for who didn't know in these years the publicity still of Inspiration (1931), ${ }^{1}$ as well as advice to have a closer look at the illuminating study

1 See for instance: http://www.doctormacro.com/Images/Garbo,\%20Greta/Annex/ Annex\%20-\%20Garbo,\%20Greta\%20(Inspiration)_01.jpg 
of David S. Shields, Still: American Silent Motion Picture Photography (Shields, 2013), ${ }^{1}$ in order to demonstrate how much stage photography was influenced by film still photography (itself strongly influenced, in the beginning, by... stage photography). They can even go further and refer to literary fiction addressing the globalization of Hollywood's imaginary in the interwar period, such as Manuel Puig's 1968 Betraying Rita Hayworth (whose plot starts in 1933 and ends in 1948). ${ }^{2}$ Others will be reminded of Bianca Castafiore, the Milanese nightingale starring in Gounod's Faust, whose first appearances in the Tintin universe go back to the 1930s as well (more precisely in King Ottokar's Sceptre). ${ }^{3}$

Even that, definitely non-European material, may prove useful in the quest for meaning. Finally, well-trained crowdsourcers may even establish that my initial example has been "stolen" from an already existing and well-organized archive, the Divadelny' ústav archive of the Theatre Institute Bratislava, which owns the copyright of this material and has kindly accepted to disseminate it via Europeana Photography, an EU funded digitization project aimed at enriching Europeana, the major European online collection for cultural heritage,${ }^{4}$ with masterpieces of early photography provided by a public-private partner consortium. ${ }^{5}$

It is in the context of, among others, Europeana Photography, that important attempts have been made to establish protocols and best procedures in the booming field of crowdsourcing techniques and strategies. Key in this regard is the work done by the EU project "Civic Epistemologies: Development of a Roadmap for Citizen Researchers in the age of Digital Culture". Various subprojects of this vast research program on the implementation of non-professional work and workers in the field of heritage culture have discussed some do's and don'ts of crowdsourcing, with fascinating examples such as the one on the recollection of oral history in Western Ireland. ${ }^{7}$

1 See: http://tmm.chicagodistributioncenter.com/IsbnImages/9780226013268.jpg

2 https://primaveraenlasopa.files.wordpress.com/2012/01/manuel2bpuig2b-2bla2btra ici25c325b3n2bde2brita2bhayworth.jpg? $\mathrm{w}=261 \& \mathrm{~h}=400$

3 The story was serialized in 1938-1939, and the redrawn and colorized in 1947.For an image of the singer, see: http://en.tintin.com/images/tintin/albums/07sceptre/ C07\%2028\%20A3.jpg

$4 \mathrm{http}: / /$ www.europeana.eu/portal/

5 http://www.europeana-photography.eu/index.php?en/75/divadeln-stav

$6 \mathrm{http}: / / \mathrm{www}$. civic-epistemologies.eu/

7 This case study within the "Civic Epistemologies" project is presented here: http://www.civic-epistemologies.eu/wp-content/uploads/2014/07/CIVICEPISTEMOLOGIES_D4.1_Ethnograhic-Pilot-Report_v1.0.pdf 
Moreover, crowdsourcing is far from being an isolated phenomenon: it is a vital part of the tendency towards participatory culture and the shift from consumer to prosumer culture. In that sense, a discussion of what is considered one of the major roads to increase participation and prosumerism, namely crowdsourcing, is a significant and necessary contribution to a broader debate on the necessary democratization of culture and the role that digitization can play in this process.

Yet in spite of the sometimes spectacular achievements of this successful example, crowdsourcing as a method of reading photographs foregrounds important issues that should prevent us from embracing it as a kind of magical solution to our never ending and often frustrating yet also infinitely exciting encounter with the medium of photography. In what follows, I would like to address some of these problems, not in order to discredit crowdsourcing per se (such a gesture would be a sign of obscurantism as well as elitism), but in order to disclose some of its inescapable limitations. In the background, my observations are much indebted to a recent book by Yves Citton, L'avenir des humanités (2013), a powerful contribution to the necessary role of humanities (and humanist methods and theories) in future society.

The first problem of crowdsourcing is of course the possible confusion between information and knowledge. The former refers to "what" we can know, the latter to "why" it is important to know it. This confusion, which in practice shrinks knowledge to information and foregrounds the quantity of information at the expense of the quality of knowledge, reduces human cognition, which relies on interpretation, to a mere mechanism of recognition - the importance of which is key in current research on pattern recognition and token identification of raw visual data on the internet.

Once again, it would be a mistake to question the proper usefulness of recognition and information mechanisms, which are the very basis of any interpretation whatsoever, but there should be room to make a strong claim for the crippling effects of the reduction of knowledge to information. Information should never be an aim in itself, it is only valuable as the starting point of a process of interpretation, which necessarily involves a critical reflection on the meaning of informational data. Crowdsourcing, true, is not by definition strictly informationoriented. But the emphasis on technical metadata is so strong that it 
pushes the public's input towards the completion of missing data, more particularly of data linked with type and token identification, which is often also the only crowdsourcing input that can be exploited by human or non-human machines that have to extract further information from it. Technical metadata, specifying objective, often quantifiable and measurable (who made the picture? when was it made? which techniques were used? who owned it?, who is the subject represented? etc.), is of course absolutely necessary, but as the more sophisticated metadata systems such as Iconclass, the leading system in art history, ${ }^{1}$ clearly show, the correct handling of many technical metadata frequently supposes acts of interpretation, which blur the boundaries between information and knowledge. ${ }^{2}$

A second problem, directly related to the first one, is the reduction of knowledge to primarily cognitive or intellectual aspects. Contrary to information, which can be processed in strictly mechanical ways, knowledge is a multilayered and multidimensional phenomenon in which embodied emotions play an essential role, just as social, political, and ideological belief systems, which transform interpretation into a temporal process (and not just a stimulus-response process). It is this complexity that highlights the gap between information and knowledge. One of the major differences between the processing of information and the production of knowledge is that the latter depends on a destruction as well as a reappropriation of the initial information flow or data. On the one hand, the information is interrupted by the interpretive act; on the other hand, it is also reconfigured via new combinations, which obey concerns that are not just intellectual. Interpretation is always dependent on the future meaning or usefulness of the knowledge one wants to produce, and in this process, the decisive element is time. The disruption the information flow is only possible if one can "stop" this flow and take the time to reflect on the data, whereas the interpretation that produces new knowledge is made in light of an idea of the future and may engender a radical acceleration of time.

Here as well, one should stress that, theoretically speaking, the temporal complexity of knowledge production can perfectly be present in crowdsourcing. However, the very emphasis on recognition does

1 http://www.iconclass.nl/home

2 In the aforementioned "Civic Epistemologies" project, a detailed "best practice" list of metadata can be bound on pages 58-59 of the document quoted in footnote 9 . 
not encourage appropriationnist approaches of the photographic archives. More radical forms of interpretation will have to be found in other directions. And let us not forget either that the increasing commodification of photographic heritage is another handicap in this regard. Crowdsourcing is often used to foster intellectual property rights policies, not to enable the audience to reuse the material as raw data, in a creative mash-up or remix intention.

Third and finally, crowdsourcing may not be the preferred match with the essential feature of culture in the historical period that is both symbolized and shaped by a technological medium such as photography: the creative tension between the unique artefact on the one hand and serialization on the other hand, or, if one prefers, between culture and the creative industry (not to be confused with Adorno's and Horkheimer infamous "culture industry"). The industrialization of culture has a multiple impact on the traditional uniqueness of cultural artefacts. Beyond the dramatic changes brought about by the technical reproducibility of works of art, as studied by Walter Benjamin in a number of studies that have achieved absolute hegemony, one should also stress, as highlighted by scholars such as Matthieu Letourneux (2014), the double shift from "one shot" productions to "serial" production and, perhaps even more importantly, the shift from a "material" (i.e. mediatized) work of art to its "demediated" (i.e. dissociated from any specific medium) content - a shift that is the condition sine qua non for the smooth migration of the work, now dematerialized as content, to other formats and other media, to as many other formats and other media as possible. In the age of "convergence culture" (Jenkins, 2006), the work of art is no longer a material object but in idea or, if one would put in a literary terminology, it is no longer a concrete text but an abstract model or architext (Genette, 1992). In the world of transmedia storytelling, for instance, the world is less a story or a plot than a set of features - characters on the one hand, a universe on the other hand that are open to narrative reinterpretation by its users and makers (two categories that tend to overlap more and more).

The relationship with current crowdsourcing practices may not be self-evident, but it is crucial nevertheless. If it is true that one of the secret dreams of crowdsourcing is to attenuate, if not to radically abolish the intolerable lack of information that surrounds most photography (even the photography already well-clad with all kind of possible metadata), 
the current practice of crowdsourcing misses both the unicity of the original work of art, which can never be reduced to a list of captions and explanations, and the fundamental openness of the serialized work of art, which is characterized by the steady increase of cross-medial and transmedial migrations and creative reappropriation whose objective is not to shed light on the existing material but to make something new out of it. As it is often practiced today, crowdsourcing may leave us with the illusion that the meaning of a photograph is not to be found beyond the relationship with a picture and its beholder. It is now time to make a claim for much more radical and open forms of collective interpretation that position the meaning of the image in the future, thus accepting the possible abandon of its relationship with the original document.

To summarize: of course, the critique of crowdsourcing should be taken cum grano salis. As already stated, the benefits of this new reading mechanism are various and dramatically important. However, the success crowdsourcing mechanisms and operations should not make us overlook some of its important problems: first, the confusion between information and knowledge; second, the reduction of interpretation to an instantaneous stimulus-answer scheme that puts between brackets the vital temporal dimension of interpreting; and third its relative indifference toward the basic structural tensions of modern creative industries. Crowdsourcing is a necessary aspect or partner in the reading of photographs, but there should be room for other, more challenging ways of living with pictures: 'thick' and more contextualized reading is what comes to mind almost immediately (Geertz, 1973), but it should be possible to go beyond, for instance by exploring, in the spirit of Latour (1999), the poetics of articulation, comprising "the activities of connecting, conceptualizing and creating - thus bridging the divide between subject and object, idea and matter, words and world" (Highfill 2014: 97), and why not by dreaming of new ways of making things strange, instead of clear, in a controlled way, without falling prey to the charm of obscurantism, thanks to the sobering influence of social and intersubjective regulation. 


\section{References}

Baetens, J. (2012). L'exemple, un mal nécessaire ?. Méthis, 4, 135-148.

Citton, Y. (2013). L'Avenir des humanités. Paris : La Découverte.

Genette, G. (1992), The Architext. Berkeley: University of California Press.

Geertz, G. (1973). The Interpretation of Culture. New York: Basic Books.

Gitelman, L. (Ed.) (2013). Raw Data Is an Oxymoron. Cambridge, Mass.: MIT Press.

Hergé (1974). King Ottokar's Scepter. New York: Little. Brown Books for Young Readers (first French book publication in 1939).

Highfill, J. (2014). Modernism and Its Merchandise. The Spanish Avant-Garde and Material culture, 1920-1930. University Park: Penn State University.

Jenkins, H. (2006). Convergence Culture. New York : New York University Press.

Latour, B. (1999). Pandora's Hope: Essays on the Reality of Science Studies. Cambridge, Mass.: Harvard University Press.

Letourneux, M. (2014). Penser la sérialité : supports, genres, culture médiatique (Unpublished Habilitation Essay, Paris Ouest La Défense)

Puig, P. (2009) Betrayed by Rita Hayworth. Champagin, Ill.: Dalkey Archive Press (first Spanish book publication in 1968).

Shields, D. S. (2013). Still: American Silent Motion Picture Photography. Chicago: Chicago University Press. 